\title{
MAIS O PROGRAMA EDUCAÇÃO E A GESTÃO DO TRABALHO ESCOLAR: UM ESTUDO EM DUQUE DE CAXIAS/RJ1
}

\author{
Regis Argüelles da Costa ${ }^{2}$
}

\begin{abstract}
Resumo
O objetivo geral desse artigo é contribuir para a compreensão crítica dos rebatimentos de políticas de inspiração neoliberal de Terceira Via na gestão do trabalho escolar docente, ao nível da rede escolar municipal. Analisamos a implantação e gestão do Programa Mais Educação (PME) em uma escola de Duque de Caxias, município do estado do Rio de Janeiro. Concluímos que as condições estruturantes para a ampliação da jornada ao nível da gestão do trabalho escolar - financiamento da política, formação do profissional e condições do espaço escolar - foram bem articuladas pela escola pesquisada, ainda que com limitações.
\end{abstract}

Palavras-chave: Gestão do trabalho escolar; trabalho docente; Programa Mais Educação.

\begin{abstract}
The general objective of this article is to contribute to the critical understanding of the neo-liberal policies inspired by Third Way in the management of schoolwork at the level of the municipal school network. We analyzed the implementation and management of the More Education Program (PME) in a school in Duque de Caxias, municipality of the state of Rio de Janeiro. We conclude that, at the level of the schoolwork management, the structuring conditions for the extension of the workday - policy financing, professional training and conditions of the school were properly articulated by the researched school, albeit with limitations.
\end{abstract}

Keywords: Schoolwork management; teaching work; More Education Program.

\section{Introdução}

O modelo gerencial proposto pela classe dominante para administração pública no Brasil, a partir dos anos de 1990, concebe o braço social do Estado fundamentalmente como um provedor de serviços que deve sujeitar-se às leis do mercado. A descentralização, o foco no cliente, o estabelecimento de metas, e a avaliação são, nesse sentido, entendidas como medidas capazes de gerar

\footnotetext{
1 DOI: https://doi.org/10.22409/tn.16i29.p4559

2 Professor da Faculdade de Educação da UFF. Doutor em Educação (PPGE/UFRJ). É pesquisador associado ao Laboratório de Investigação Escola, Poder e Estado (IM-UFRRJ), ao Núcleo de Estudos - Tempos, Espaços e Educação Integral (UNIRIO) e ao Grupo de Pesquisa Estado, Trabalho, Educação e Desenvolvimento (UFF). E-mail: rarguelles@gmail.com.
}

TrabalhoNecessário- www.uff.br/revistatrabalhonecessario: ano 16, №29/2018 
padrões de eficácia a um serviço público tomado pela burocracia, pela baixa qualidade do atendimento oferecido, pelo desperdício, e pela corrupção.

Herdado da teoria da administração de empresas, o modelo gerencial sugere ao setor público a realização de parcerias com o setor privado, a utilização do voluntariado como força de trabalho, o foco das ações na população em situação de extrema pobreza, e o controle social dessas ações. Para Melo e Falleiros (2005), tais medidas caracterizam o estágio de desenvolvimento do programa neoliberal da Terceira Via no Brasil, que almeja a reconstrução do Estado Social, mediante a transferência de recursos e responsabilidades públicas para instituições privadas.

Sendo a educação uma prioridade das frações comprometidas com a difusão do programa da Terceira Via, as políticas para o setor passaram por importantes inflexões. A orientação neoliberal do aparelho de Estado foi incorporada ao texto e aos desdobramentos da Lei de Diretrizes e Bases da Educação (Lei no 9.394/96), ainda que com contradições (LEHER, 2010). A União, mormente através do Ministério da Educação, reforçou sua participação nas políticas para a escola de ensino fundamental, como é o caso do Programa Dinheiro Direto na Escola (PDDE), do FUNDEF/FUNDEB, e dos programas de avaliação em larga escala, como a Prova e a Provinha Brasil, e o Índice de desenvolvimento da educação básica (Ideb).

Tais políticas vêm reestruturando a profissão docente, especialmente a gestão do trabalho escolar, trazendo consigo elementos de precarização e flexibilização para o cotidiano da escola pública (OLIVEIRA, 2004). Políticas semelhantes vêm sendo aplicadas em diversos países da América Latina (CASSASUS, 2001), intensificando as responsabilidades $e$ as atividades cotidianas de docentes e, de em diversos graus, fragilizando suas condições de trabalho. Esse trabalho procura avaliar os impactos de uma política federal deveras representativa nesse sentido - o Programa Mais Educação (PME), de 2007 - na rede municipal de educação de Duque de Caxias, município da Baixada Fluminense, dando especial atenção aos processos locais de implantação e gestão. Considerando que o PME impõe novas tarefas para as Secretarias de Educação e para as escolas municipais, como a gestão local do trabalho docente incorpora essas determinações? Quais são as tensões e 
adaptações que elas imprimem à administração da escola pública e ao trabalho escolar cotidiano?

Para tentarmos responder tais questões realizamos, no ano de 2015, entrevistas semiestruturadas com as equipes diretivas de diversas escolas municipais de Duque de Caxias (RJ). Nesse artigo iremos apresentar os resultados da pesquisa de campo na Escola Beta, localizada em Imbariê, $3^{\circ}$ distrito municipal. ${ }^{2}$ A escola foi indicada pela Secretaria Municipal de Educação de Duque de Caxias (SMEDC) como exemplo satisfatório de experiências do PME na rede. ${ }^{3}$ Adotamos questionários como instrumentos de pesquisa, que foram previamente remetidos aos entrevistados. As perguntas propostas no instrumento de pesquisa trataram das mais diversas responsabilidades que envolvem a implantação e gestão do contraturno nas escolas, com foco em suas relações com a gestão do trabalho docente escolar. Para tanto, problematizamos a gestão do trabalho docente escolar a partir da análise de alguns condicionantes presentes no PME: a contratação e remuneração de pessoal, a utilização e prestação de contas das verbas repassadas, a formação oferecida, e a utilização dos espaços para além da sala de aula. Após a gravação e transcrição, o material foi submetido à análise de conteúdo. Incorporamos ao material de análise documentos referentes aos mais diversos níveis administrativos que envolvem $o$ PME. ${ }^{4}$

O trabalho está dividido em quatro itens, contando com esta introdução. A seguir, veremos como desenho do Programa Mais Educação procura interferir em diversas dimensões da gestão escolar. As características da rede municipal caxiense, e os reflexos da implementação e gestão do PME na escola serão, então, apresentados e analisados no próximo item. Por último, teceremos algumas considerações finais, à guisa de conclusão do trabalho.

\footnotetext{
${ }^{2}$ Essa pesquisa é parte de um projeto de Tese de doutorado, concluído em 2016. Realizamos investigações semelhantes em outras quatro escolas, e também na SMEDC.

${ }^{3}$ Tal critério metodológico se explica pelo fato de imaginarmos que experiências precárias da política seriam vazias de significados para o pesquisador, dado a superlotação e precariedade da maioria dos espaços escolares caxienses.

${ }^{4}$ Os nomes atribuídos às entrevistadas e à escola são fictícios.
}

TrabalhoNecessário- www.uff.br/revistatrabalhonecessario: ano 16, №29/2018 


\section{O Programa Mais Educação e as novas modalidades de gestão da escola pública}

Conforme afirmamos na introdução, a educação é uma das prioridades de setores comprometidos com a difusão do programa neoliberal da Terceira Via, os quais adquiriram maior proeminência a partir do governo de Fernando Henrique Cardoso (1995-2002). O governo de Lula da Silva (2003-2010), em teoria de oposição ao de seu antecessor, manteve relações orgânicas com o empresariado na definição de políticas, causando tensões com suas bases originárias. Dessa forma, as proposições da Terceira Via não encontraram no governo Lula da Silva um adversário - em verdade, foram ali ampliando sua área de influência e sedimentando-se (NEVES, 2008; MARTINS, 2009).

Saviani (2007) viu no Plano de Desenvolvimento da Educação (PDE, Dec. no 6.094/07), lançado para o período de 2007-2022 pelo MEC, um dos principais expoentes da relação mais orgânica entre o PT e a classe empresarial. Para a elaboração do PDE foram privilegiadas as interlocuções com a última, o que é atestado pelo próprio texto do programa, o qual afirma assumir integralmente a agenda do Movimento Todos pela Educação. ${ }^{5}$

Uma das ações mais salientadas do PDE pelo governo federal foi o Programa Mais Educação (PME), cujo objetivo é oferecer formação integral aos alunos do nível fundamental, através de oficinas no contraturno escolar. A oferta do PME destina-se, preferencialmente, às escolas localizadas em territórios de 'vulnerabilidade social', de baixo desempenho no Ideb, e com índices iguais ou superiores a $50 \%$ de estudantes pertencentes a famílias participantes do Programa Bolsa Família. Além dessas premissas, o PME atende a cidades com população igual ou superior a 18.844 mil habitantes. ${ }^{6}$

\footnotetext{
${ }^{5}$ O Compromisso Todos pela Educação foi um movimento lançado em setembro de 2006, em São Paulo. Identificando-se como uma iniciativa da sociedade civil, o movimento conta com representantes importantes empresas ou fundações a elas ligadas, como o Grupo Pão de Açúcar, Fundação Itaú Social, Fundação Roberto Marinho, Instituto Ayrton Senna, Instituto Ethos, Instituto Itaú Cultural, entre outros. (Cf. Saviani, 2007).

${ }^{6} \mathrm{O}$ atual governo instituiu o Programa Novo Mais Educação, através da Portaria no 1.144 , de 10 de outubro de 2016. Trata-se de uma versão mais pragmática de seu antecessor, com ênfase destacada na utilização da ampliação da jornada para aulas de reforço em Língua Portuguesa e Matemática, as "competências" definidas internacionalmente como sinônimos de qualidade da educação escolar. Houve também uma maior centralização da gestão, que agora está sob responsabilidade de uma empresa prestadora de serviços ao MEC.
}

TrabalhoNecessário- www.uff.br/revistatrabalhonecessario: ano 16, №29/2018 
As ações socioeducativas indicadas para o contraturno escolar não se limitam ao currículo mínimo do ensino fundamental, contemplando os campos das artes, da cultura, do esporte e do lazer; contudo, as atividades de 'acompanhamento pedagógico' em língua portuguesa e matemática são obrigatórias. Elas podem acontecer em espaços não escolares, agregando o 'compartilhamento comunitário' das responsabilidades educativas, em uma 'dinâmica de redes' (PI 17/2007, art. 1²).

As oficinas de contraturno devem ocorrer semanalmente, de modo a garantir aos participantes 7 horas diárias de atividades, ou 35 horas semanais de turno e contraturno. A escolha e desenvolvimento das oficinas pelas unidades escolares devem integrar-se o Projeto Político-Pedagógico dessas últimas. São ministradas por profissionais denominados oficineiros, que podem ser alunos de licenciaturas ou educadores sociais. Esses profissionais têm status de voluntários ${ }^{7}$ e recebem uma ajuda de custo mensal para a realização das ações no contraturno, que cobre os gastos de deslocamento. Segundo o MEC, em 2014 - PME atingiu cerca de 50.000 escolas públicas, ampliando sua cobertura em mais de $300 \%$ em apenas dois anos. ${ }^{8}$

Apesar de reafirmarem sua dívida com os ideais e as experiências históricas de ampliação da jornada escolar, é possível mapear alguns elementos originais que compõem as propostas do PME, como a possibilidade de desconcentração das atividades desenvolvidas no contraturno. Essa intenção vem a reboque das metas de reorganização da gestão e da oferta da educação pública, a partir da presença mais ativa de outros setores governamentais públicos e privados (secretarias de esporte, cultura e saúde; empresas, Igrejas, ONGs, fundações privadas).

O convite à realização de atividades em outros espaços para além da escola se baseia no juízo que, sozinha, esta não dá mais conta da demanda

\footnotetext{
7 A Lei do Voluntariado ( $n^{\circ 9.608 / 1998)}$ considera que o serviço voluntário é atividade não remunerada e sem vínculo empregatício, que tenha objetivos cívicos, culturais, educacionais, científicos, recreativos ou de assistência social (art. 1ํ). O voluntário pode vir a ser ressarcido pelas despesas oriundas do desempenho das atividades (art. $3^{\circ}$ ).

${ }^{8}$ Estes números devem ter sofrido uma redução considerável dados os cortes no orçamento federal, que vêm sendo praticados com maior intensidade desde 2015. Na rede municipal de Duque de Caxias várias escolas suspenderam o contraturno, por conta do não repasse das verbas do PDDE-Educação Integral. Parece que o mesmo vem ocorrendo em outros municípios da Região Metropolitana do Rio de Janeiro. Todavia, não conseguimos encontrar publicações do MEC ou estudos a respeito desse problema.
}

TrabalhoNecessário- www.uff.br/revistatrabalhonecessario: ano 16, №29/2018 
ampliada por educação dos jovens da sociedade do conhecimento; em contrapartida, as cidades oferecem uma série de espaços públicos e privados que podem ser utilizados em atividades formativas para os alunos.

Em um trabalho bastante elucidativo sobre os objetivos do terceiro setor para a ampliação da jornada escolar, Guará (2003) qualifica a escola como espaço possuidor de especificidade dentro do processo educativo, chamando atenção para o fato de que "nenhuma instituição pode ou consegue hoje, isoladamente, responder por toda a formação da criança e do adolescente" (GUARÁ, op. cit., p. 39). As ONGs reúnem, por sua vez, características tais como a "flexibilidade e a liberdade curricular" (GUARÁ, idem, p.40) e a proximidade com a comunidade, o que as permite associar o conhecimento às demandas da vida prática com maior facilidade que escolas, dada a rigidez curricular dessas últimas.

A junção da educação escolar com os projetos socioeducativos desenvolvidos pelo poder público e pelas ONGs resulta, segundo a autora, em uma política pública que combina educação e proteção. Essa é marca de uma concepção de educação integral voltada especialmente para àqueles em "situação social vulnerável" (GUARÁ, ibid., p. 37), campo em que as ONGs possuem larga experiência, muitas vezes fazendo uso de trabalho voluntário.

Ao se integrarem ao PME, esse conjunto de proposições demonstra a força da articulação política do terceiro setor ligado ao empresariado, no sentido de pautar o debate sobre a ampliação da jornada nas escolas públicas. Há o estímulo às parcerias com ONGs para execução da política, dada a sua alegada capacidade de diálogo com crianças e jovens em situação de vulnerabilidade. A sua flexibilidade, por sua vez, garante maior capacidade de adaptação às diferentes demandas das comunidades atendidas. Por outro lado, as escolas públicas são categorizadas como instituições burocráticas enrijecidas e apartadas do cotidiano da comunidade em que atuam. Trata-se, sobretudo, da crítica ao Estado como o locus do arcaico e da ineficiência, que precisa ser oxigenado através de relações amplas com a "sociedade civil", retratada como espaço asséptico de produção do consenso e da paz social (FONTES, 2010).

A solução do voluntariado para a questão do trabalho docente indica a opção pelo aprofundamento do processo de precarização dos profissionais da educação, com respaldo ativo do empresariado. O oficineiro está sujeito a um estágio profissional que conjuga remuneração baixíssima com grandes desafios

TrabalhoNecessário- www.uff.br/revistatrabalhonecessario: ano 16, №29/2018 
didáticos-pedagógicos, tais como a condução de oficinas em turmas multisseriadas, compostas por alunos com distorção idade/série e dificuldades de aprendizagem. Isso sem contar a provável dificuldade de integração do planejamento de oficinas com o trabalho desenvolvido pelos docentes do turno, elemento fundamental na tomada de decisões, e em possíveis correções de rumo do contraturno.

No PME, o questionamento da centralidade pedagógica da escola é contrabalançado pelo estímulo ao controle burocrático de secretarias de educação e unidades escolares. Elas são corresponsáveis pela adesão, coordenação e controle dos recursos sob a rubrica do PME, através do Sistema Integrado de Monitoramento e Controle (SIMEC/MEC); pela gestão de pessoal; e na contribuição com parte dos recursos destinados à gestão da política. Destacamos, por exemplo, as tarefas de escolha dos estudantes que devem participar das oficinas, de busca por parcerias na vizinhança para o desenvolvimento do contraturno, de condução do processo seletivo e de contratação dos oficineiros.

É deveras importante para o andamento da política nas escolas a atuação do Professor Comunitário, que na rede municipal de Duque de Caxias é conhecido como Coordenador de Escola do Mais Educação, doravante Coordenador. Esse profissional cuida do acompanhamento pedagógico e administrativo do PME na unidade escolar, devendo ser professor(a) desta; a sua seleção e remuneração são parte da contrapartida acordada com o governo municipal quando da adesão à política federal (SEB/MEC, 2014). ${ }^{9}$

Afora a mencionada contrapartida dos governos locais, a maior parte dos recursos que financiam o Programa Mais Educação provêm do FNDE/MEC. Os repasses são recebidos na conta bancária de cada escola em três parcelas anuais, discriminadas em verbas de custeio e de capital, sob a rubrica PDDE/Educação Integral. O montante de repasses varia de acordo com as atividades escolhidas, e com o número de alunos nelas inscritos. As unidades escolares, por intermédio de seus Conselhos Escolares, devem utilizar os recursos na compra de materiais pedagógicos e de apoio às oficinas (os kits), na

${ }^{9} \mathrm{O}$ MEC estabelece alguns critérios para algumas ações, como é o caso da escolha dos alunos das escolas que devem participar do PME. Contudo, a escola conta com forte autonomia nessa, e em outras decisões, naturalmente.

TrabalhoNecessário- www.uff.br/revistatrabalhonecessario: ano 16, №29/2018 
ajuda de custo aos oficineiros, e até na aquisição de bens permanentes, desde que se ateste, nesse último caso, a sua necessidade no desenvolvimento das atividades de contraturno. Vale sublinhar que, nesse processo, também é função do Conselho Escolar propor ações e fiscalizar o uso dos repasses do PME.

Esse conjunto de responsabilidades demanda da equipe diretiva, Conselho Escolar e Coordenador uma considerável capacidade de articulação de tarefas essenciais para a ampliação da jornada escolar. Não nos restam dúvidas que o PME intensifica em tempo e em complexidade o trabalho destes profissionais, que envolve se informar, planejar, executar e avaliar a política. Além disso devemos considerar que, na maioria dos casos, suas escolas não se encontram preparadas para receber alunos em contraturno. Nessa realidade, muitas vezes agravada por um contexto político que exige resultados em curto prazo, aumentar o tempo de escolarização pode significar mais precarização, ao invés de mais educação.

O que fica patente em um programa com as características do PME é a necessidade de articulação subordinada da escola com outros centros de poder (Poulantzas, 1985), especialmente com as secretarias municipais, ONGs, os Ministérios e Secretarias executivas. Tal necessidade se torna mais urgente quando é a escola mínima que o recebe, pela sua previsível carência de espaços e de pessoal habilitado para prover o contraturno, ainda que apenas para parte de seus alunos. Sem esse suporte, dificilmente o cotidiano precário do turno não será reproduzido no contraturno do Mais Educação, empobrecendo a experiência como um todo (Cavaliere, 2009). Vejamos, a seguir, como a implantação e gestão do PME em Duque de Caxias procurou lidar com essas questões.

\section{A gestão do trabalho escolar no PME em Duque de Caxias: a escola Beta}

Duque de Caxias é um município da Região Metropolitana do Rio de Janeiro. De acordo com os dados do último censo do IBGE, possui com população de cerca de 880.000 hab., distribuídos em 467 km². O município está dividido em quatro distritos administrativos: Duque de Caxias, 1ำ distrito; Campos Elísios, 2 distrito; Saracuruna, 3ำ distrito, e Xerém, 4ำ distrito. Destaca-se por abrigar um dos polos-petroquímicos mais importantes da Região Sudeste, além de outras indústrias. Possui uma das maiores receitas de impostos do Brasil (arrecadação em 2015 superou a casa de 1,3 bilhões de reais) e, por

TrabalhoNecessário- www.uff.br/revistatrabalhonecessario: ano 16, №29/2018 
conseguinte, verbas próprias para a educação na casa de 450 milhões de reais. ${ }^{10}$ A despeito desse orçamento, o município ocupa apenas o $52^{\circ}$ lugar em termos de IDH no Estado do Rio $(0,711)$, e figura entre os municípios mais violentos da Baixada Fluminense (Cano e Santos, 2007). Os resultados nas avaliações em larga escala promovidas pelo governo federal são tampouco animadores, com maior gravidade nos anos finais do ensino fundamental (INEP/MEC, 2014).

O município administra 143 escolas e 34 unidades de educação infantil, onde são distribuídas 79.200 matrículas. Trata-se de uma rede de escolas marcada por problemas de infraestrutura - especialmente os da falta d'água, da exiguidade de espaços e da superlotação. Algumas escolas ainda dividem seu dia letivo em quatro turnos (INEP/MEC, op.cit.).

A partir das análises de Souza (2014) entendemos que a distribuição de escolas pelo território caxiense obedeceu, historicamente, a trâmites que pouco respondiam às reais necessidades da população local. A construção ou não de um prédio escolar em um bairro dependeu de uma série de fatores de caráter estritamente político, tais como capacidade de articulação do vereador com o prefeito, ou se a localidade em questão estaria sob influência de lideranças afinadas com quem ocupava o executivo e/ou o legislativo municipal. A luta por melhoria das existentes e pela abertura de novas escolas esteve na agenda dos movimentos sociais caxienses, que em diversos momentos se organizaram para garantir o direito à educação pública.

Em Duque de Caxias, o PME está sob a responsabilidade da Departamento de Projetos Educacionais (DPE), que está subordinado à Subsecretaria de Planejamento e Projetos Educacionais, uma das quatro subsecretarias existentes na estrutura da SMEDC. Uma equipe de três professoras da rede coordena todas as ações do Programa, dividindo sua atuação por distrito administrativo, o que dá pouco mais de 40 escolas sob a responsabilidade de cada professora. O Núcleo de Atendimento aos Conselhos Escolares, também lotado na SMEDC, cuida da gestão de recursos financeiros, orientando as direções de escola e gestoras pedagógicas em relação à prestação de contas das verbas recebidas após a adesão. 


\subsection{A Escola Beta}

Trata-se de uma unidade escolar trabalhando no limite da capacidade. A Escola Beta funciona em 4 turnos, nos quais se distribuem 1.236 matrículas, conforme a Tabela 1 abaixo. Para se ter uma ideia da superlotação, basta lembrarmos que a Escola Alfa, um CIEP, atende apenas 890 matrículas nos dois níveis do EF. Na Escola Beta, o PME é oferecido a 150 alunos, ou seja, 1,21\% do total de matrículas.

Só o Mais Educação, então, usa a capacidade toda da escola? Toda. Porque é uma escola de quatro turnos. E além dos quatro turnos na sede, mais dois turnos no anexo. (...). Como é que você vai ampliar mais alguma coisa em uma escola que já funciona de 7 às 11,11 às 3,3 às 7,7 as 10 ? (SORAYA, op.cit.)

$E$ aí você não tem banheiro para essas crianças, vestiário dentro da escola. (ANA MARIA, op.cit.)

\section{TABELA 1 - Número de matrículas da Escola Beta, por nível/modalidade de ensino}

\begin{tabular}{lc}
$\begin{array}{l}\text { Nível/Modalidade } \\
\text { de ensino }\end{array}$ & Matrículas \\
\hline Pré-escola & 216 \\
\hline $\begin{array}{l}\text { Séries iniciais do } \\
\text { EF }\end{array}$ & 818 \\
\hline EJA & 199 \\
\hline Educação Especial & 3 \\
\hline Total & 1.236
\end{tabular}

Fonte: Censo Escolar, INEP/MEC, 2014.

A professora Soraya, pedagoga com especialização em gestão escolar, 18 anos de rede municipal, e há 12 anos ocupando a direção da Escola Beta, sua única escola na rede, alegou que a superlotação se dá por conta da carência de outras unidades na região. Assim, o tipo de interferência que a escola sofreu em seu espaço construído, ao longo dos anos, foi determinado pela necessidade de se inaugurar novas salas de aula. Outras benfeitorias, tais como quadra de esportes, sala de leitura, e sala de direção não foram contempladas nas obras. 
O PME chegou em 2010 na Escola Beta. Quanto à formação para a gestão da política, recordou-se a Orientadora Pedagógica:

Nós tivemos, na realidade quando nós recebemos o PDE-Escola, a primeira vez em 2008, cujo o Programa Mais Educação faz parte do Plano de Desenvolvimento da Educação, nós recebemos sim uma boa formação de técnicos do MEC, para que pudéssemos ter um embasamento técnico, para prepararmos o nosso PDE. Isso se deu em 2008, depois em 2009, em 2010 chegou o Programa se não me engano - em 2010, o PME. (CAMILA, orientadora Pedagógica da Escola Beta, 2015).

Eles formaram antes?

É, a nossa formação, digamos assim, ela começou antes realmente de recebermos o projeto. Agora, especificamente, formação específica para receber o Programa Mais Educação, não me recordo. (SORAYA, diretora-geral da Escola Beta, 2015).

Apesar de não haver formação oferecida pelo MEC, todos da equipe confirmaram que a SMEDC, à época, mantinha um grupo responsável pelo PME, trabalhando em conjunto com as escolas. A formação era, nesse caso, de responsabilidade do governo municipal que, conforme a orientadora pedagógica Clara, oferecia formação aos monitores, que também tinham reuniões periódicas com os Coordenadores. Por volta de 2011 as formações se restringiram às videoconferências, segundo a diretora.

Desde o início do PME, a gestão local entendeu que a verba oferecida pela adesão seria irrecusável por parte da escola.

E os professores aqui sabem também o quanto esse recurso do Mais Educação ajuda toda a escola. É importante que o professor saiba disso. Houve uma época de final de gestão agora mais recente, que o município foi abandonado. ${ }^{11}$ Nós não tínhamos

\footnotetext{
$11 \mathrm{O}$ andamento do PME sofreu um forte impacto negativo quando a SMEDC, em fins de 2012, determinou a suspensão do cargo de Coordenador do Mais Educação em todas as escolas. Essa suspensão da contrapartida do governo local para com o Programa foi mais uma ação que compôs a crise do serviço público municipal, nos três últimos meses do mandato de José Camilo Zito frente à prefeitura (2009-2012). Com maior gravidade a partir da confirmação de que o exprefeito não iria disputar o segundo turno nas eleições daquele ano, várias escolas tiveram que funcionar em meio período, devido à falta d'água, já que os carros-pipa que as abasteciam suspenderam o fornecimento por atraso no pagamento, ou devido à falta de pessoal de limpeza, também por conta de atrasos nos repasses da prefeitura às empresas prestadoras de serviços. Em: $\quad$ http://odia.ig.com.br/portal/rio/escolas-com-as-bicas-secas-1.435943 http://www.caxiasdigital.com.br/blog/escola-municipal-bom-retiro-em-duque-de-caxias-temcondicoes-precarias/ e http://www.jornalmassa.com.br/2012/08/107838-estudantes-de-duque-de-
}

TrabalhoNecessário- www.uff.br/revistatrabalhonecessario: ano 16, №29/2018 
nada, nós não tínhamos nem pagamento, nosso pagamento ficou atrasado. Os funcionários de apoio, que são os mais castigados, que ganham muito pouco, estavam sem receber pagamento. Nós não tínhamos folha de ofício, não tinha nada no depósito. Foi a verba do Mais Educação que nos ajudou. (SORAYA, op.cit.).

As verbas contribuíram principalmente na construção de espaços para atividades pedagógicas, como a Sala de Filosofia ${ }^{12}$ e uma área coberta no pátio da escola. A cobertura nos chamou atenção logo em nossa primeira visita à unidade, pois sobre o telhado construído existe um painel onde se lê "Espaço do Mais Escola"13. Por conta de a escola ter poucas áreas de sombra, em uma região que faz muito calor o ano todo, a cobertura é usada como abrigo no recreio pelos alunos, e também em atividades de educação física. Em um município em que os recursos são centralizados em outros centros de poder, ter recursos, ao nível da escola, foi considerado fundamental por toda equipe diretiva.

As oficinas oferecidas à época eram recreação, horta/sustentabilidade, karatê, artesanato, letramento e matemática, 3 vezes por semana. Antes de oferecer o PME, a Escola Beta mantinha aulas de reforço para alunos com dificuldade de aprendizagem. No primeiro ano, as atividades eram de segunda a sexta; com a autorização da SMEDC por dias intercalados, os 150 alunos foram distribuídos em 5 turmas de 30 cada, que se revezam nos espaços da horta escolar, no "Espaço Mais Escola", na Sala de Leitura, e na Sala de Filosofia (ver Imagem 1, abaixo).

caxias-ficam-sem-aula-segundo-a-prefeitura-devido-a-falta-dagua.html. Acessados em: 03 de novembro de 2015.

$12 \mathrm{O}$ projeto do Núcleo de Estudos Filosóficos da Infância (NEFI/UERJ), denominado "Em Caxias a filosofia em-caixa? A escola pública aposta no pensamento', possui financiamento pelo CNPq e está na Escola Beta desde 2009. Coordenado pelo Prof. Dr. Walter Kohan (FE/UERJ), o projeto se propõe a encontros filosóficos com os alunos, com objetivo de repensar a educação através da filosofia (Júnior, 2013). Na Escola Beta esse projeto possuiu uma sala própria que também é utilizada em atividades do PME.

${ }^{13}$ Mais Escola foi a versão caxiense do PME durante a gestão de José Camilo Zito (2009-2012). Tratou-se apenas de mudança de nome, à medida que nada substancial foi efetivamente incluído ou suprimido.

TrabalhoNecessário- www.uff.br/revistatrabalhonecessario: ano 16, №29/2018 
Imagem 1 - Oficina de Letramento do PME (Escola Beta)

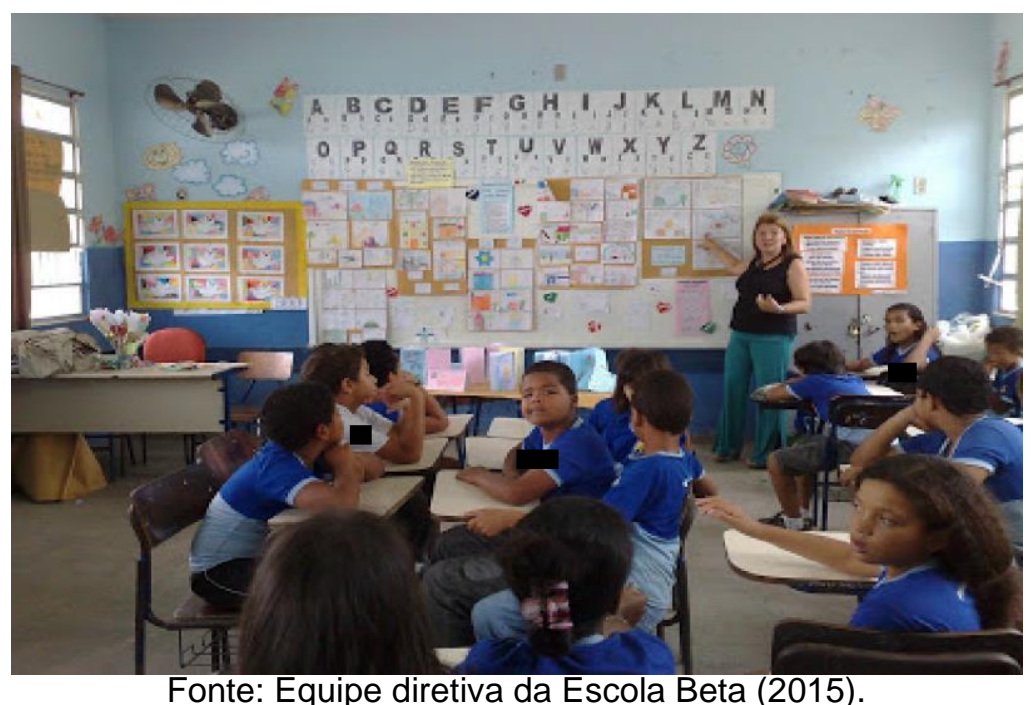

A relação com os oficineiros, que foi ressaltada como problemática pela SMEDC, mormente por conta da adequação ao horário de trabalho e as frequentes desistências, não foi detectada nessa escola. Ao contrário, toda a equipe ressaltou uma relação positiva com toda a equipe de voluntários. Alguns, inclusive, estão na unidade desde o início do PME ali.

As visitas de pesquisa à escola, num total de quatro, nos deixaram a impressão que a figura da diretora da Escola Beta é essencial para a manutenção do Programa. Seu engajamento na condução do Programa, aliado ao fato de estar há quase 20 anos na escola, dá à política possibilidades adequadas de desenvolvimento, contrastando com outras direções, que parecem entender a presença do PME como mais um problema para a gestão escolar, que já enfrenta batalhas diárias na rede municipal caxiense. Dessa forma, esse achado de pesquisa confirma as considerações de Maurício, Melo e Gonçalves (2015), que associam o andamento do Programa ao nível de engajamento e de formação da direção.

A despeito de tal característica ser uma vantagem para a Escola Beta e, provavelmente, para outras unidades dirigidas por profissionais capazes de dirigir e potencializar a experiência de ampliação da jornada, há de se ponderar que tal determinação e empenho por parte da gestão denota as deficiências no suporte às escolas na implantação e gestão do PME, indo de encontro às contrapartidas dos Ministérios e Secretarias federais, bem como à própria contrapartida municipal, que poderia atuar no sentido de apoiar efetivamente as direções na

TrabalhoNecessário- www.uff.br/revistatrabalhonecessario: ano 16, №29/2018 
condução do Programa, mais ainda após a extinção do cargo de Coordenador do Mais Educação. Ademais, a dependência de gestores(as) que se debrucem sobre os problemas cotidianos do PME para sua satisfatória efetivação no cotidiano da unidade, indica a ampliação das funções sociais da escola, conforme caracterizada por Algebaile (2009).

O governo municipal também não adotou uma conduta que se possa avaliar como colaborativa na manutenção do Programa. As ações mais cobradas nesse sentido foram a presença do Coordenador Escolar do Mais Educação, e a questão da carência de espaços escolares.

Por exemplo, não nos permitiram nem o Coordenador. Nós conseguimos encontrar alternativas, percebe, dentro da escola, para fazer com que o programa ande e aconteça. Porque a figura do coordenador, ela é fundamental. Essa seria uma das contrapartidas da rede municipal, que foi retirada. $E$ a outra contrapartida, seria o quê? O próprio prédio. (SORAYA, ibid.).

A extinção da função de Coordenador do Mais Educação foi bastante negativa para o desenvolvimento do PME na Escola. Sobrecarregou o trabalho da equipe diretiva, que precisou se utilizar de diversas estratégias para manter as atividades semanais de contraturno, mesmo elas ocorrendo em dias alternados. Além disso, as escolas perderam a ponte de contato com a SMEDC, que também funcionava como espaço de troca de experiência entre os Coordenadores. A solução encontrada pela SMEDC foi contratar "Articuladores": profissionais de ensino médio que percorrem algumas escolas semanalmente para levar e entregar relatórios de controle das atividades do PME nas escolas, um caso que aponta para um processo de precarização e fragilização da política. Estes relatórios devem ser preenchidos mensalmente pelas equipes diretivas, algo bastante próximo de uma prestação de contas.

\section{Considerações Finais}

Para fins de síntese destacamos alguns achados de pesquisa que podem servir como exemplos cuja extrapolação nos parece razoável, no sentido de contribuir para o esclarecimento da problemática desenvolvida neste trabalho. Em primeiro lugar, que a ação em rede envolvendo diversos níveis e atores dos 
setores público e privado, uma das premissas de gestão do PME, apresentou diversas inconsistências no caso de Duque de Caxias. Exemplos nesse sentido foram a progressiva burocratização das relações entre o MEC e as escolas, reduzidas ao SIMEC, e a substituição das formações presenciais por cursos à distância. À medida que a Escola Beta possui acesso precário à rede mundial de computadores, a proposta de formação on-line parece-nos inócua.

A extinção do cargo de Coordenador de Escola do Mais Educação, em fins de 2011, foi fundamental para a precarização da experiência. Ampliou a quantidade de trabalho sob responsabilidade da equipe diretiva das escolas e determinou a redução dos dias de oferta do contraturno. A solução encontrada pelo governo municipal foi a contratação de profissionais denominados Articuladores, cuja função era basicamente entregar e receber das direções um relatório de controle das atividades do PME. Assim, uma função que poderia ter importante papel pedagógico no desenvolvimento das atividades nas escolas ficou eclipsada por outra meramente burocrática e não-especializada.

A herança histórica de investimento mínimo na educação básica fica explicitada na Escola Beta na questão dos espaços para as atividades do PME. Trata-se de uma escola superlotada que precisa abrigar, além dos 4 turnos diários, 3 contraturnos por semana. E tudo isso sem parceiros públicos ou privados de espaço para dividir esse contingente de alunos. É fundamental destacar, nesse sentido, que as propostas de parceria com o terceiro setor para ampliação da jornada escolar impõe maiores obstáculos às periferias das grandes cidades, como é o caso de Duque de Caxias, à medida que as ONG's concentram seu raio de ação no município do Rio de Janeiro.

Os repasses financeiros vinculados ao PME foram valorizados por toda equipe diretiva da Escola Beta. Considerando que as escolas municipais de Duque de Caxias não recebem verba própria por parte do governo, a diretora declarou achar curioso algum gestor negar o contraturno em suas escolas. Com esse montante foram feitas obras e melhorias das quais toda a comunidade escolar passou a se beneficiar, e não apenas os matriculados no PME. E, mesmo com a baixíssima ajuda de custo, a Escola Beta afirmou não ter maiores problemas com a contratação e manutenção dos oficineiros. Pareceu-nos que a questão do sucesso do PME na Escola Beta está ligada à formação do diretor e sua equipe, bem como as suas longevidades nos respectivos cargos.

TrabalhoNecessário- www.uff.br/revistatrabalhonecessario: ano 16, №29/2018 
Os dados reforçaram que, ao nível da gestão do trabalho escolar, as condições estruturantes para o desenvolvimento de uma proposta de ampliação da jornada na escola pública são o financiamento da política, a formação do profissional e as condições do espaço escolar. Todas, aliás, organicamente associadas ao trabalho docente, em suas diversas dimensões constituintes. Conforme essa pesquisa e parte da literatura sobre o tema aponta, o trato adequado dessas condições pode resultar em boas experiências como a da Escola Beta, ainda que esta sofra com limitações oriundas de sua posição de poder no campo educacional, o que ficou patente na questão do espaço escolar, muito citada ao longo das entrevistas. Não as levar em consideração ou trata-las de forma tangencial pode resultar em desperdício de dinheiro público, precarização e intensificação do trabalho realizado no cotidiano da escola pública. Portanto, as escolas que aderem ao PME são, em essência, dependentes de ajudas das instâncias de poder superiores.

\section{Referências Bibliográficas}

ALGEBAILE, Eveline. Escola pública e pobreza no Brasil: a ampliação para menos. Rio de Janeiro: Lamparina; Faperj, 2009.

BRANCO, Veronica e GUIMARÃES, Sandra. A construção da educação integral e a formação continuada de professores alfabetizadores no Município de Porecatu Paraná. In: COELHO, Lígia Martha (org.). Educação integral: história, políticas e práticas. Rio de Janeiro: Rovelle, 2013, p. 155-172.

BRASIL. Lei n. 9.394, de 20 de dezembro de 1996. Estabelece as diretrizes e bases da educação nacional. Diário Oficial da União, Brasília, DF, 23 dez. 1996.

. Portaria Interministerial n. 17, de 20 de abril de 2007. Institui o

Programa Mais Educação. Diário Oficial da União, Brasília, DF, 24 abr. 2007.

Decreto $\mathrm{n}^{\circ}$ 6.094, de 24 de abril de 2007. Dispõe sobre implantação do Plano de Metas Compromisso Todos pela Educação. Disponível em: http://www.planalto.gov.br/ccivil_03/_ato2007-2010/2007/decreto/d6094.htm, acessado em 11 de maio de $20 \overline{15}$.

CANO, Ignácio e SANTOS, Nilton. Violência letal, renda e desigualdade no Brasil. $2^{\mathrm{a}}$ ed. Rio de Janeiro: 7Letras, 2007.

CASASSUS, Juan. A reforma educacional na América Latina no contexto de globalização. In: Cadernos de Pesquisa, n. 114, nov. 2001. p. 7-28. 
CAVALIERE, Ana Maria. Escolas de tempo integral versus alunos de tempo integral. In: Em Aberto, Brasília, v. 22, n. 80, p. 51-63, abr. 2009.

COELHO, Lígia Martha. (org.). Educação integral: história, políticas e práticas. Rio de Janeiro: Rovelle, 2013.

COELHO, Lígia Martha e HORA, Dayse. Políticas públicas de educação integral em jornada escolar ampliada e trabalho educativo: docência questionada ou precarização do trabalho docente? In: COELHO, Lígia Martha (org.). Educação integral: história, políticas e práticas. Rio de Janeiro: Rovelle, 2013, p. 204-224.

COUTO, Lúcia; SANCHES, Ana Lucia; RAMOS, Sonia. Com mais, a criança faz muito: experiência da rede municipal de Diadema (SP). In: MOLL, Jaqueline (org.). Caminhos da educação integral no Brasil: direito a outros tempos e espaços educativos. Porto Alegre: Penso, 2012, p. 424-433.

FONTES, Virgínia. O Brasil e o capital-imperialismo: teoria e história. Rio de Janeiro: MES/FIOCRUZ/EPSJV; Editora UFRJ, 2010.

GUARÁ, Isa. Educação, proteção social e muitos espaços para aprender. In: CENPEC (org.). Muitos lugares para aprender. São Paulo: CENPEC/Fundação Itaú Social/Unicef, 2003, p. 31-45.

INEP/MEC. Microdados do Censo Escolar. Brasília: 2014. Disponível em: http://download.inep.gov.br/microdados/micro_censo_escolar_2014.zip. Acesso em: 18 jan., 2016.

JÚNIOR, José Ricardo P. S. Filosofia com crianças: dos saberes da infância à infância dos saberes. 2013. 93f. Dissertação (Mestrado em Educação) UERJ, Rio de Janeiro.

KAVAI, Sandra Helena. O Programa Mais Educação em Duque de Caxias/RJ: analisando uma política de ampliação escolar. 2013. 126 p. Dissertação de Mestrado em Educação. PPGE, UFRJ, Rio de Janeiro, 2013.

LEHER, Roberto. 25 anos de educação pública: notas para um balanço do período. In: GUIMARÃES, Cátia (org.). Trabalho, educação e saúde: 25 anos de formação politécnica no SUS. Rio de Janeiro: EPSJV, 2010, p. $29-72$.

MARTINS, André Silva. A direita para o social: a educação da sociabilidade no Brasil contemporâneo. Juiz de Fora/MG: Editora UFJF, 2009.

MINISTÉRIO DA EDUCAÇÃO (MEC). Documento elaborado pelo MEC orienta gestores de escolas. Disponível em: http://portal.mec.gov.br/index.php?option=com_content\&view=article\&id=19212:do cumento-elaborado-pelo-mec-orienta-gestores-das-escolas\&catid=211. Acesso em: 16 ago., 2015.

MELO, Marcelo e FALLEIROS, lalê. Reforma da aparelhagem estatal: novas estratégias de legitimação social. In: NEVES, Lúcia. (org.). A nova pedagogia da 
hegemonia: estratégias do capital para educar o consenso. São Paulo: Xamã, 2005.

MOLL, Jaqueline et alli. Caminhos da educação integral no Brasil: direito a outros tempos e espaços educativos. Porto Alegre: Penso, 2012.

NEVES, Lúcia. Determinantes das mudanças de conteúdo das propostas educacionais no Brasil dos anos 90: período Itamar Franco. In: NEVES, Lúcia (org.). Educação e política no limiar do século XXI. $2^{\underline{a}}$ ed. Campinas, SP: Autores Associados, 2008, p. 5-58.

OLIVEIRA, Dalila. A reestruturação do trabalho docente: precarização e flexibilização. Educação e Sociedade, Campinas, vol. 25, n. 89, p. 1127-1144, set. dez., 2004.

PENNA, Maura. Educação musical e educação integral: a música no Programa Mais Educação. Revista da ABEM, Londrina, v. 19, n. 25, p. 141-152, jan. jun. 2011.

PINTO SANTOS, Claudia e CARLOS VIEIRA, Roberto. Reflexão sobre o Programa Mais Educação na rede estadual de ensino da Bahia. In: MOLL, Jaqueline et alli. Caminhos da educação integral no Brasil: direito a outros tempos e espaços educativos. Porto Alegre: Penso, 2012, p. 336-344.

POULANTZAS, Nicos. O Estado, o poder, o socialismo. $3^{\underline{a}}$ ed. Rio de Janeiro: Ed. Graal, 1985.

SAVIANI, Demerval. O Plano de Desenvolvimento da Educação: análise do projeto do MEC. Educação e Sociedade. Campinas, vol. 28, n. 100 - Especial, p. 1231-1255, 2007.

SEB/MEC. Manual operacional de educação integral. Brasília, DF, 2014.

SIOPE/FNDE. Relatório Resumido de Execução Orçamentária (Duque de Caxias). Brasília: $2014 . \quad$ Disponível em: https://www.fnde.gov.br/siope/relatorioRREOMunicipal2006.doc Acessado em: 10 jan., 2016.

SMEDC. Manual do Mais Escola. Duque de Caxias, RJ, 2012.

SOUZA, Marlúcia Santos de. Escavando o passado da cidade: história política da Cidade de Duque de Caxias. Duque de Caxias, RJ: APPH-CLIO, 2014.

Recebido em: 05 de novembro de 2017.

Aprovado em: 28 de março de 2018.

Publicado em: 13 de junho de 2018. 